\title{
Nurse practitioners' perceptions of their ability to enact leadership in hospital care
}

\author{
Julia van Kraaij MSc, RN, PhD Student ${ }^{1}$ (D) | Catharina van Oostveen PhD, RN, Senior \\ Researcher $^{2,3}$ (D) | Hester Vermeulen PhD, RN, Professor of Nursing Science ${ }^{1,4}$ | \\ Maud Heinen PhD, RN, FEANS, Senior Researcher ${ }^{1}$ | Anita Huis PhD, RN, FEANS, Senior \\ Researcher $^{1}$ | Marian Adriaansen PhD, RN, Professor of Nursing Science ${ }^{4}$ | Jeroen Peters \\ PhD, MScN, RN, Program Director and Senior Researcher Master Advanced Nursing Practice ${ }^{5}$
}

\footnotetext{
${ }^{1}$ Scientific Center for Quality of Healthcare (IQ healthcare), Radboud University Medical Center, Radboud Institute for Health Sciences, Nijmegen, The Netherlands

${ }^{2}$ Spaarne Gasthuis Academy, Spaarne Gasthuis Hospital, Haarlem, The Netherlands

${ }^{3}$ Erasmus School of Health Policy \& Management, Erasmus University Rotterdam, Rotterdam, The Netherlands ${ }^{4}$ HAN University of Applied Sciences, Nijmegen, The Netherlands

${ }^{5}$ HAN University of Applied Sciences, Master Advanced Nursing Practice, Nijmegen, Netherlands
}

\section{Correspondence}

Jeroen Peters, PhD, MScN, RN, HAN University of Applied Sciences, Master Advanced Nursing Practice, P.O. Box 9029, 6500 JK, Nijmegen, Netherlands.

Email: jeroen.peters@han.nl

\begin{abstract}
Aims and objective: To gain insight into nurse practitioners' (NP) leadership roles in Dutch hospital care, by exploring the perceptions regarding their current leadership role and the differences with their previous role as a registered specialised nurse.

Background: To meet today's challenges of the increasing healthcare demands, the employment of NPs is proliferating. NPs have the ideal position to play a pivotal role within healthcare reforms, yet full expansion of their scope of practice and expertise is having limited success. Long-term sustainability of NPs depends on the ability to perform and develop a leading role.

Design and methods: This qualitative descriptive study was conducted in fifteen Dutch hospitals. Data were collected from April-July 2018, and purposive sampling was used for eighteen semi-structured interviews. This study is conducted and reported according to the COREQ checklist.

Results: Three main themes concerning NPs' current leadership role emerged, and they were all linked to a successful positioning of NPs. All themes seemed to be of influence on NPs' scope of daily practice. Direct patient care was emphasised, and leadership on other levels appeared to be underused. Most NPs desired to reshape their profession. However, unprofitable use of their leadership skills especially on professional and organisational level and lack of supportive factors seemed to hinder them.

Conclusions: An adequate use of leadership is crucial for role development and positioning of NPs. Further development of the NP profession can help to better differentiate between the tasks of registered specialised nurses and NPs.
\end{abstract}




\section{KEYWORDS}

advanced practice nursing, barriers, facilitators, leadership, nurse practitioner's role, qualitative research, registered specialised nurse

\section{1 | INTRODUCTION}

Rising healthcare costs, technological innovations, integrative care, the ageing population and the need to pursue equity increase the pressure on healthcare systems to maintain their quality and high safety outcomes (Australian College of Nursing, 2015; Delamaire \& Lafortune, 2010). Nurses play a central role in this, as they work across all sectors, deliver care in a broad range of health services and represent the largest group of health providers (Australian College of Nursing, 2015). The Institute of Medicine claimed that this is a remarkable opportunity for nurses to employ leadership competences and meet the challenges of an uncertain healthcare climate (Denker, Sherman, Hutton-Woodland, Brunell, \& Medina, 2015).

Besides the increased focus on leadership among nurses, innovative advanced roles are proliferating, and the employment of nurse practitioners (NP) is emerging (Vulto \& Vianen, 2009; Zwijnenberg \& Bours, 2012). Compared to registered specialised nurses, NPs have developed more knowledge and skills, and possess other properties, such as the achievement of new practice, responsibility for health promotion and significant role autonomy (Hamric, Hanson, Tracy, \& O'Grady, 2014). According to Elliott, Begley, Sheaf, and Higgins (2016), long-term sustainability of NPs depends on the ability to perform and develop the leadership component of their role.

Denker et al. (2015) concluded that nurses' leadership development is a complicated process since today's health care is fast-paced and quickly changing. Whether NPs take the lead in these areas relies upon their personal qualities and characteristics, demands of the patient, characteristics of the organisation and health policy issues (Elliott et al., 2016; Fealy et al., 2018; Hamric et al., 2014). At this moment, it is unclear how NPs in the Netherlands have developed their leadership role during the educational programme and how their current competencies differ from the ones they possessed as a registered specialised nurse. Likewise, scant information on NPs' experiences regarding their leadership role and position is available.

\section{2 | BACKGROUND}

NP is the overall designation for nurses with an advanced degree in a nursing programme including a specific focus area of practice. NPs are expected to have a significant impact in the development of practice and professionalisation of their teams, and to improve the quality and safety of healthcare services (Elliott et al., 2016). NPs must understand the bigger networks around the patient that may influence the provision of care, recognise the need for innovation and implement strategies to improve safety and quality of care.

\section{What does this paper contribute to the wider global clinical community?}

- An adequate use of leadership is crucial for role development and positioning of nurse practitioners;

- Although differences in tasks between nurse practitioners and registered nurses appeared to be clear, nurse practitioners mainly enact leadership on clinical level;

- Nurse practitioners, healthcare organisations, educational institutions and professional associations together should create a full and unambiguous scope of nurse practitioners' expertise and practice to clearly show the added value of this profession in the healthcare system.

NPs are more autonomous in clinical decision-making from a medical perspective, and they are more often consulted by the multidisciplinary teams than are registered specialised nurses (Begley et al., 2010; Zwijnenberg \& Bours, 2012). Although registered specialised nurses are also expected to enact leadership in daily practice, many policymakers believe that NPs have additional responsibility for professional development and practice innovation. Besides, it is assumed that NPs can connect their leadership performance with their job performance evaluation (Begley et al., 2010).

Hamric et al. (2014) distinguished four different leadership roles: clinical, professional, system and political leadership. Leadership tasks of NPs at system and political level are still underdeveloped because NPs are mainly occupied with clinical care and case-load responsibility (Elliott et al., 2016). Even though NPs value the nonclinical aspect of their profession, they frequently reported barriers to participate in education and research activities (Dicenso \& Bryant-Lukosius, 2010). The roles of NPs have been widely studied, although with a primary focus on generic features of the profession and the direct influence of NPs on the healthcare system (Carryer, Gardner, Dunn, \& Gardner, 2007; Gardner \& Gardner, 2005). Additionally, a broad interpretation of the term "Advanced Practice" exists worldwide between countries, which makes it difficult to formulate a clear and consistent scope of practice (Gardner \& Gardner, 2005; Schober, 2016), and thus the extent of the NP leadership role.

\subsection{Aim}

This study aims to gain insight into NPs' leadership roles in Dutch hospital care, which could contribute to a better understanding of 
their scope of practice and its influential factors. The study has the following research objectives:

- To explore NPs' perception regarding their current leadership role and to discover which barriers and facilitators they experience;

- To explore the experienced differences in leadership role between the NP position and the previous position as a registered specialised nurse.

\section{3 | METHODS}

This study is conducted and reported according to the Consolidated Criteria for Reporting Qualitative Research (COREQ) checklist (Tong, Sainsbury, \& Craig, 2007).

\section{1 | Design}

A qualitative descriptive design was used to obtain insights into the perceived leadership role of NPs. The aim of qualitative description is to provide a rich and unbending description of an event (Neergaard, Olesen, Andersen, \& Sondergaard, 2009), and it contributes to exploring people's experiences and opinions (Price, Jhangiani, \& Chiang, 2015).

\subsection{Registered specialised nurses and NPs in the Netherlands}

\subsection{1 | Registered specialised nurses}

A registered specialised nurse is a registered nurse with an associate degree basic registration in the Dutch registry for healthcare professionals including supplementary education in their area of expertise (European Qualifications Framework (EQF) level 4 or 6). Registered specialised nurses' competencies are defined in accordance with the CanMEDS system (Lambregts \& Grotendorst, 2012; V\&VN, 2018).

\subsection{2 | NPs}

In the Netherlands, after having completed a two-year Master of Advanced Nursing Practice (MANP), one can register as NP ("Verpleegkundig specialist" in Dutch), which is a legally protected title in the Dutch registry for nurse practitioners (Vulto \& Vianen, 2009; V\&VN, 2018). The total study load consists of $3,360 \mathrm{hr}$ or 120 EC. The master programme is offered by nine Universities of Applied Sciences and focuses on the acquisition of function-specific skills and expertise. The programme is based on the apprenticeship model of learning, which refers to a combination work-based learning in their healthcare settings and universities. The programme can
TABLE 1 Characteristics of the study population $(\mathrm{N}=18)$

\begin{tabular}{|lllll} 
& & & Experience & \\
ID & Gender & Age & as NP & Hospital setting \\
\hline P1 & Female & 52 & 3 & Community \\
P2 & Female & 46 & 5 & Community \\
\hline P3 & Male & 40 & 5 & Community \\
P4 & Female & 53 & 4 & University \\
\hline P5 & Female & 54 & 3 & Community \\
\hline P6 & Female & 56 & 4 & Community \\
\hline P7 & Female & 52 & 4 & Community \\
\hline P8 & Female & 60 & 1 & Community \\
\hline P9 & Female & 51 & 6 & Community \\
\hline P10 & Female & 36 & 3 & Community \\
\hline P11 & Female & 39 & 1 & Community \\
\hline P12 & Female & 43 & 4 & Community \\
\hline P13 & Female & 42 & 4 & Community \\
\hline P14 & Female & 43 & 6 & Community \\
\hline P15 & Female & 43 & 4 & University \\
\hline P16 & Male & 55 & 8 & Community \\
\hline P17 & Female & 56 & 3 & Community \\
\hline P18 & Female & 41 & 3 & University \\
\hline & & & & \\
\hline
\end{tabular}

be followed after an initial nursing degree programme is completed at bachelor level and is classified as EQF level 7. NPs work in somatic or mental health care and their competencies are also based on the CanMEDS system (Lambregts \& Grotendorst, 2012). Vulto and Vianen described five competencies that distinguish NPs from registered specialised nurses in the Netherlands: (a) clinical reasoning and the ability to independently make a diagnosis; (b) possessing medical knowledge and skills to bridge the gap between physicians and nurses; (c) being informed about recent scientific research; (d) being involved in division of management plan; and (e) showing leadership in innovation processes.

\section{3 | Participants}

A homogeneous purposive sampling of nurse practitioners across various specialties and hospitals in the Netherlands was chosen. This sampling method can be used for describing a specific subgroup with its aim to decrease variation (Palinkas et al., 2015). In this study, five eligibility criteria for NPs were selected: (a) sufficient proficiency in the Dutch language; (b) at least three years of work experience as a specialised registered nurse before starting the MANP; (c) currently two to six years of working experience as NP; (d) NP specialisation is equal to the specialisation as registered nurse; and (e) the MANP degree must have been obtained at one of the nine Universities of Applied Sciences in the Netherlands that offer the MANP programme. The above-mentioned work experience is required to ensure sufficient leadership development. Characteristics of the study population can be found in Table 1. 
TABLE 2 Interview guide topics

\begin{tabular}{ll} 
Demographic information & $\begin{array}{c}\text { Age, kind of hospital working, MANP graduation year, years of } \\
\text { experience as a specialised registered nurse and an NP, type of } \\
\text { specialised nurse education, work relationship, number of NPs } \\
\text { at department, introduction year NP at department }\end{array}$ \\
\hline Current leadership role & Looking back at a successful day at work, when did you feel \\
yourself a nursing leader? & How did this happen? Did you make a difference and for whom? \\
Which skills were important? What was the surroundings' \\
influence? \\
How did you develop yourself regarding your leadership \\
competencies? \\
How do your personality, surrounding and education contribute? Do \\
you have role models? \\
What barriers and facilitators do you experience in your leader- \\
ship development? \\
In comparison with your function as a specialised registered \\
nurse, where do you experience differences? \\
Influence, responsibility, quality of care, research initiatives, policy- \\
related activities, knowledge, financial matters, networking
\end{tabular}

Invitations by e-mail were sent to programme directors of six Master of Advanced Nursing Practice programmes in the Netherlands. A convenience sample was selected to include various sizes, geographic locations and diversity in education. Subsequently, five programme directors selected students who graduated in the years 2012 to 2017 and invited these by e-mail to take part in this study. An information flyer about the research including the possibility to sign up was published at a Facebook page for NPs. At one university, this study was also promoted at a NP alumni event. NPs who agreed to participate in the study were contacted by the principal investigator (JK) to plan a face-to-face interview and they received additional information about the research. The interviews took place at a time and location convenient for the participants. Allowing the participant to decide on where the interview will be held is not only a technical matter since power relations will not be encouraged when doing so (Herzog, 2005). At one university, none of the alumni responded to the invitation. In total, eighteen participants were included.

While conducting the interviews, it appeared that three participants did not meet the required work experience as NP. Two participants had graduated for a year and one participant for more than six years. Despite the specification of the strict inclusion criteria, the interviews were continued. After data saturation had been reached with the other fifteen interviews, these three interviews were analysed to see whether differences appeared when not meeting the exact inclusion criteria on work experience. The duration of work experience did not prove to be an obstacle to the overall picture of their leadership development. Following an iterative decision-making process with all authors, they were included in the final sample.

\subsection{Data collection}

\subsection{1 | Interviews}

One researcher (JK) conducted eighteen in-depth semi-structured interviews from April up till June 2018. Conducting this type of interview makes it possible to seek deeper information and knowledge than one can obtain from surveys or structured interviews (Johnson, 2011). All participants were interviewed once. The interviews took between 45-60 min and were digitally recorded after participants' permission, and field notes were taken immediately after each interview. An interview guide used during the interviews (Table 2) functioned as a tool to embellish consistency in data collection. The guideline was based on Hamric et al.'s (2014) description of NPs' leadership domains and their corresponding competencies. In addition, the guideline was discussed with a multijurisdictional Advisory Board including seven researchers (JK, $\mathrm{CO}, \mathrm{HV}, \mathrm{MH}, \mathrm{AH}, \mathrm{MA}$ and JP) and one pilot interview was conducted. For improvement of interviewing skills, it can be helpful to have a more experienced researcher listen to the interview tapes (Streubert \& Carpenter, 2001). Therefore, the quality of the interviews was evaluated with the senior investigator (CO) who is an interviewing expert. Participants were asked if they wanted to receive the transcript to give comments. One participant requested a few minor changes.

\subsubsection{Role of the researchers}

$\mathrm{JK}$ is a female registered nurse and $\mathrm{PhD}$ student. $\mathrm{CO}$ is a female registered nurse with a postacademic degree and working as a senior advisor and researcher. Personal relationships between the participants and interviewer did not exist. Participants knew about the role and education of the interviewer before the interview started. The Advisory Board members (HV, MH, AH, MA and JP) are all senior researchers and were involved in creating the topic list, analysis and interpretation of the findings and finalising the article.

\section{5 | Data analysis}

The interviews were conducted, transcribed verbatim, analysed independently and coded. Two researchers (JK, CO) were directly 
involved in the process of the inductive and constant comparative analysis. All field notes and transcripts were coded into themes and categories in order to form a conclusion. To strengthen the rigour, the trustworthiness of the data and interpretations were considered (Milne \& Oberle, 2005). Several main themes emerged from the data, and they were refined various times. The codes, categories and themes were also discussed with members of the Advisory Board. Whenever there was a disagreement, discussions and clarifications were continued until consensus was reached. This led to a distillation of data into thematic description. Data analysis was conducted in Dutch, using Atlas-ti version 8.2.0 software.

\subsection{Ethical considerations}

Participation was voluntary, participants were assured of confidentiality and anonymity, and they had the right to withdraw at any point without prejudice. Prior to conducting the interviews, participants were asked to sign an informed consent form. All data were to remain confidential, and the anonymity of the participants was guaranteed by dissociation of names. The medical ethics review board of the Radboud Institute of Health Sciences approved the study but waived the need for ethical approval as the study had no effect on the participants' well-being. According to the board's rules and legislations, data will be archived for 15 years and saved under identification numbers.

\section{4 | RESULTS}

All participants were convinced that being a nurse leader had a positive effect on the quality of daily care as well as on the positioning of NPs. Main differences with their previous function as a specialised registered nurse were found in the degree of accountability and responsibility in patient care. Issues mentioned included patient consultation, demands from the patient and influence over money issues. The analysis of the data has led to the emergence of three major themes concerning NP's current leadership role: (a) focus on clinical leadership; (b) shaping the NP profession; and (c) essential components for NP's practice.

\section{1 | Focus on clinical leadership}

Taking the lead in the development of high-quality care and direct patient care was pointed out in all interviews. Participants indicated a higher level of medical knowledge and a different sense of responsibility towards patient and colleagues. Integration of knowledge, skills and attributes is required for competency building. These three indicators were identified from the interviews.

\subsection{1 | Clinical knowledge}

Nursing expertise and advanced knowledge of diseases of the patient population were present and identified in the interviews. Participants mentioned knowledge as an important factor to further elaborate their role as NP. A majority stated that they developed more advanced medical knowledge during and after their MANP education. Some of them indicated that this expansion in clinical knowledge supported them to carry more responsibilities. According to the participants, having sufficient knowledge provides more confidence-which was directly related to being and feeling a nurse leader.

You are able to ask more questions in consultation. You notice connections and you can better understand the cause of the problem. Medical knowledge has grown, which has been nice. I certainly made a big step forward.

(Participant 15).

Our leadership (NPs'; ed.) is mainly focused on knowledge and expertise on activities you often execute.

(Participant 3)

\subsection{2 | Skills for professional development}

Participants mentioned several skills that helped expand tasks and responsibilities, such as adaptive and reflective capacity, setting and keeping personal boundaries, taking matters into own hands and effective communication skills.

A substantial number described themselves as the "spider in the web," based on their coordinating and connecting role in daily practice. It appeared that the majority of the participants fulfilled this role, even without mentioning this expression. Participants frequently mentioned that they acted as the binding factor between various disciplines in hospitals, like physicians, nurses and management.

In my team, I would describe myself as the spider in the web. Ensuring that the patient care runs well and to get things done. If problems arise, or people are sick and at home, I have to come up with a solution.

(Participant 4)

All participants were convinced that conducting research assisted in enhancing the quality of care and the development of the profession. Some of them were actively involved in conducting research, while others stated that they did not have the ambition because they preferred to be active in direct patient care.

[...] using research activities to explore the exact problem. Thanks to this development, I think my love for practice-oriented research has arisen.

(Participant 12)

Some of the participants' descriptions of their current role also included policy-related activities. For example, few participants were active in supporting substitution of hospital care with primary care and in financial affairs like managing budgets or cost-effectiveness studies. 
Nonetheless, several participants indicated that their activities were mainly focused on clinical care due to high workload on patient care and focus on medical practice.

In my opinion, as a nurse leader I also need to manage budgets [...] I keep track of the number of patients and how much money we spend on it.

(Participant 9)

Most participants fulfilled a role in professional associations varying from secretary to board member. For some participants, this involved a monodisciplinary collaboration with other NPs, while others joined associations focusing on their own specialty population. These activities were seen as a way to encourage knowledge sharing and promotion, networking and to create unambiguity about the profession. Knowledge is also shared by giving presentations and training programmes. Few participants indicated that they teach at universities and participate at national congresses.

I think knowledge sharing is the most important factor. That people learn about certain diseases, how to recognise them and what you can do about it. I think that is important. And I like doing that.

(Participant 15)

Some participants mentioned that they were involved in educating NPs in training or in coaching registered nurses within the hospital.

That is our strength as NP I believe. Especially people who just... who are anxious about it, who do not want to be at the forefront and whose network is less clear [...]; yes, we need to help those people.

(Participant 12)

\subsection{3 | Attributes for the improvement of patient care}

Fundamental to the ideas of all participants was the intrinsic drive and high feeling of responsibility to deliver high-quality patient care. This appeared to be the driving force in their leadership experience since they were all convinced of having a significant impact on clinical practice. Repeated references to "being responsible for," "serving their interests" and "patient's satisfaction" illustrate their strong connection with this theme.

Yes, my heart really lies in patient care and I feel like a nurse leader when I have clearly defined the actual problem and when I have devised a plan to resolve this.

(Participant 15)

To be primarily accountable for a patient and being an independent health professional as an NP was a challenging shift from the previous position as a registered specialised nurse. Carrying this responsibility made the participants feel capable of providing care at an advanced level.

I think a nurse leader must be able to function independently. Call a physician in the case of an event, but in general you have to know exactly how care works. Being able to act and to respond to problems [...] I think that is important. Especially the responsibility and independence.

(Participant 2)

Showing initiative was seen as important for patient care, personal development and positioning of NPs. Several participants stated that, as pioneers, they had to take the initiative to create a role for themselves in the organisation.

[...] eventually we decided to sit down with a lawyer. So, we invited one to check the exact scope of our competencies and abilities. Sometimes we are seen as nurses, and they (physicians; ed.) are like 'we will arrange it', and sometimes when it is not a good time, you are portrayed as a physician and receive unwanted responsibilities while you do not even have the authority to carry them.

(Participant 10)

Almost all participants claimed that they felt more confident in their task execution as a NP after having some experience in their profession and being familiar with the department.

[...] by doing it a lot. And when you notice that it runs smoothly, you know that you are delivering good work. This gives you confidence. I have been prescribing medicine for four years and in the first year it was different from how I do it nowadays.

(Participant 7)

\subsection{Shaping the NP role}

Different barriers and facilitators to task execution and the leadership role were indicated with regard to three subjects: (a) collaboration for a successful integration of NPs; (b) productivity growth as priority; and (c) task and goal fulfilment depending on personal characteristics and drivers.

\subsubsection{Collaboration for a successful integration of NPs}

The value of a supportive work environment was mentioned many times. For example, the physician's confidence to cede responsibility and let a NP be primarily accountable for a patient's wellbeing was seen as supportive. Besides, participants indicated that 
getting support and approval from their management was important for further advancement of knowledge and task execution at policy level.

I think it is something you have to organize with your own team and department within the big hospital. There are short lines of communication and I think management in your own department is the place where to find task commitment.

(Participant 4)

If you do not have any commitment from the management in the hospital, they would not involve us in a number of projects. This may result in having less insight and you could do much less. Thus, the management must be committed to involve the NPs.

(Participant 14)

Most of the participants indicated that being a NP and standing up for the profession was easier when working together with two or more NPs at a department. Working alone could be a barrier to an advanced leadership role.

One of my colleagues is leaving and there will be a gap. This makes me sad, first of all to miss my nice colleague, but also because I will have to fight alone now.

(Participant 10)

The participants came up with several wishes with regard to shaping their profession, for example a better and more intense collaboration with nurses and physicians; a better balance between working in the outpatient unit and ward; and more involvement in research and cross-disciplinary tasks such as policy-related or managerial and financial tasks.

It must be a combination. For me that would be a way to better position my function and distinguish it from that of the nurses in my team. To tell them 'this is my function. I execute patient care, but I also pursue other activities which I can independently perform and are given the freedom and time to actually realise them'. In my opinion, that is a must for a nurse practitioner.

(Participant 4)

\subsection{2 | Productivity growth as priority}

High clinical workload and the demand for and high focus on efficiency and productivity were seen as barriers for further development. Many participants indicated that they worked on own time to perform research and to further elaborate activities on policy level and in professional associations.
We are a company; the hospital is just a company and we are being judged on productivity rates [...] If you only focus on 'patient first', you are undermining lots of functions. In my opinion, you will definitely not get there then (practice full scope of their education and profession; ed.).

(Participant 9)

\subsubsection{Task and goal fulfilment depending on personal characteristics and drivers}

It appeared that personal skills and attributes played a substantial role in the participants' task execution. Some participants indicated the importance of standing up for yourself and of not being afraid to take responsibility if you wanted to be active in other domains. Many others, however, mainly experienced external barriers which impeded further development and they did not mention their own personal capacity, which may be of great influence.

I like to engage in the discussion because I really believe there is lots of added value; so many underused opportunities associated with this function. I actually want to tell them that we can be of great use.

(Participant 13)

For most participants, the main drive to be a NP was knowledge and skills building regarding their specialty as registered specialised nurse. Besides, authorisation to prescribing medication and the diagnostic decision-making were many times indicated as reasons to take the MANP programme. Several participants claimed that they encountered limitations in their daily practice as registered specialised nurse.

To give an example how I ended up in this position. I was confronted with my limitations as registered specialised nurse. I always resented the fact that I knew very well what treatment these patients needed while I still needed a physician to receive a signature, prescription or to put an order in the computer. All this despite the fact that I knew very well what to do with it and how to interpret results.

(Participant 13)

\section{3 | Essential parties for NP's practice}

The analysis showed that all participants had ideas about the future positioning of their function, and they were all, in some way, actively involved in seeking opportunities for role expansion and positioning. Important parties in this development were as follows: (a) healthcare organisations; (b) the MANP programme; and (c) professional associations for NPs. 


\subsection{1 | Healthcare organisations}

An established common vision between NPs and healthcare providers often turned out to be absent or underdeveloped. Most participants mentioned a lack of general awareness and clarity about the NP function among staff members. Some participants mentioned that the physician assistant role was often considered the same as the NP role, which may create friction between different disciplines. Besides, overlap in domains between nurses and physicians also appeared to have a significant impact.

Yes, sometimes they have that idea, in particular the junior physicians. They assume: 'he is going to take my job'. That is, of course, not my intention at all.

(Participant 3)

And up to the present day I am struggling with that. Even this morning, three times I was called a diabetes nurse while I thought by myself, no I am not.

(Participant 9)

Having a board for NPs hospital-wide was often mentioned as solution to create a well-known, nationally accepted profession. Though all participants were convinced of a possible positive contribution to their position, the vast majority of participants stated that they did not have a common board (yet) in their hospital or were not actively involved.

We are now in the process of setting up a NP board in the hospital, because that has not yet been well arranged. In case of any changes, they do not know who to approach because we simply do not have a board.

(Participant 2)

[...] 'now hold on', I said. 'If we cannot even agree on who we are, what we are and what we stand for, how on earth do you expect the organization to know it?'

(Participant 9)

It appeared that those involved in research were confronted with unpleasant or difficult situations in their healthcare organisation. They claimed that the hospital did not support them, and for this reason, they went looking for other opportunities to execute their research.

I wanted to do more research, but the hospital did not support me. They said: 'it does not fit you nor the hospital. It is not a university hospital and we want you to run production, we want to use you for other purposes.'

(Participant 12)

Almost all participants mentioned that they fulfil a relatively new function and that this did not come without concerns. It is feared that
NPs are the first to be cut out and fulfil a profession in a grey area, which means that especially right now it is important to show the exact added value.

Hereby, a smooth positioning is fundamental. That you never get contracted out the function. Because if you get cut out, I think we are the first to struck out at the moment things are getting difficult. We are the youngest and you cannot function without an emergency nurse, you need them in daily practice. You also need an emergency physician, you cannot function without it. I think we are of additional value until the moment it becomes problematic. You have to make sure to position yourself in a manner that everyone knows what you do, without thinking too highly of yourself.

(Participant 3)

\subsubsection{MANP programme}

All participants recognised the added value of the two-year master programme regarding the execution of their function. They especially highlighted an increase in medical knowledge and skills which gave them the opportunity to take the responsibility that this profession requires. In addition, various participants mentioned that it enabled them to further develop on personal level, that is being aware of one's limitations and responsibilities to face the demands of this new profession.

The MANP education was strongly focused on not falling back into your old job, your old way of thinking and old status. I think that situation is dangerous, because it is also safe. It feels safe to do what you used to do before, but then you will get what you previously got. You have made the switch to another job, so you should not want that. Your position has other responsibilities.

(Participant 17)

However, some participants felt that the programme did not prepare them well enough for difficulties they might encounter in practice. They wished that more attention would have been given to positioning of the function.

I think it is very important that the educational institutes address positioning of the function. Doing this during the programme has the advantage of being with like-minded people. Everyone is facing the same situation, although in different situations. Often, the question is how to position yourself or how to receive a study budget. And in my opinion the institutes are the perfect places to invite the right people to talk about it.

(Participant 3) 


\subsection{3 | Professional associations for NPs}

According to most participants, professional associations for NPs could stimulate positioning of the profession. It could help create awareness among other disciplines and patients. Besides, this could also do away with the ambiguity about the job description and responsibilities.

In my opinion, V\&VN VS (the abbreviation for the professional association representing NPs in the Netherlands), should negotiate with for example health insurances or the ministry. They have to represent the relatively small group of NPs and they have to point out, 'this is still a group of young health professionals, this is their quality'. So, a bit of appreciation, conferment or more clear rules.

(Participant 18)

\section{5 | DISCUSSION}

Three main themes were identified regarding NP role development and utilisation that highlight the barriers and enablers participants perceived to enact their leadership role. It appeared that the results emerged from these topics showed similarities, and all seemed to be of influence in the degree of accountability, responsibility and autonomy NPs experienced and possessed in their daily practice.

\section{1 | Main findings}

\subsection{1 | Focus on clinical leadership}

The results of this study confirmed that participants fulfil their nursing leadership role in different domains of clinical, professional, system and political leadership (Hamric et al., 2014). Notwithstanding, their actual performance mainly reflects the clinical leadership domain. This is commensurate with Elliott et al. (2013), who concluded that leadership domains on system and political level continue to be underestimated among NPs. Different skills and attributes for the participants' current leadership role were highlighted. For example, advanced medical knowledge was considered of great importance for leadership development. There is overlap in knowledge and skills needed for effective leadership development, that is developing skills and knowledge in the clinical leadership domain makes it easier for NPs to be active at policy level (Hamric et al., 2014). Knowledge about health policy and nursing practice was an important component for the range of skills of effective nurse leaders (Antrobus \& Kitson, 1999). However, the present study showed that NPs' contribution to high-quality care is mainly based on an increase in the degree of responsibility and accountability in clinical practice. Development of clinical skills during education and the different legislation in workplace appeared to be main differences between NPs and registered specialised nurses. Where registered specialised nurses enact their clinical leadership role to exert direct influence on patients, family and fellow healthcare providers (Patrick, Laschinger, Wong, \& Finegan, 2011), NPs are skilled in providing integrative care in complex and dynamic environments (Lamb, Martin-Misener, Bryant-Lukosius, \& Latimer, 2018). Since being competent depends on the capability to use a set of related knowledge, skills and behaviour (Epstein \& Hundert, 2002), the question arises if participants possess the required competencies to further develop their leadership role in different domains. Even though all participants possessed advanced knowledge, well-developed skills and several useful attributes, most of them said they do not yet hold the desired role, and were anxious to their further position, including more intense collaboration with nurses and physicians and being more involved in research.

\subsection{2 | Shaping the NP profession}

Being a NP nowadays seems to automatically demand a proactive attitude where taking initiative is important for role development (Mantzoukas \& Watkinson, 2006). Nevertheless, only few participants actually performed their desired work activities. These NPs were active in research and executed many tasks on policy level. The concept of positive deviance may be at play here, as it assumes that it is likely to have some individuals within a given population who have developed solutions to a complex problem (LeMahieu, Nordstrum, \& Gale, 2017). How did these participants stray from the straight path and went looking for workarounds? To overcome the obstacles that were in the way of shaping their own desired profession, for example the need for high production rates in hospitals, they found new opportunities at other places. The degree of self-efficacy seemed to play an important role: they were all confident about their added value and could clearly describe their vision as NP. Scott and Miles (2013) concluded that the level of confidence in knowledge, skills and abilities is related to leading others. They described this as leadership self-efficacy, and thus, individuals with high self-confidence probably have more belief in the ability to be successful and having an internal locus of control.

"Claiming autonomy in clinical practice" was regularly referred to in the interviews. This included being directly responsible for a patient's well-being. Attaining autonomy relies upon the capability to make independent decisions, on possessing sufficient knowledge and on having reflective capacity (Skår, 2008). In this regard, the participants mainly mentioned autonomously prescribing medicine and autonomous decision-making, but it also appeared that there were still many differences in the extent to which authorisations had been conferred. Petersen, Keller, Way, and Borges (2015) concluded that institutional and legal restrictions can negatively affect the level of autonomy in NP practice. Even in the Netherlands, NPs have to clear hurdles in their institutions, despite development of legislation and regulation at national level. One of the aims of the professional association for NPs is to nationally represent all NPs for further development of the profession and its position in the Dutch healthcare system. 


\subsection{3 | Essential components for NP's practice}

The overlap in scope of practice between NPs and physicians had at times created tensions between the parties. The combination of nursing care and medical care may also provoke difficulties in creating autonomous practice for NPs (Weiland, 2015). A possible explanation is the still-present hierarchy in hospitals, where physicians are in a leading position and nurses cannot succeed in creating a position of one's own (van Oostveen, Goedhart, Francke, \& Vermeulen, 2017).

According to the participants, workplace context and organisation-level factors were of great influence on NPs' task allocation. They indicated factors such as high productivity rates, time shortage, lack of support at the organisational level or healthcare budget cuts. Some studies recognised organisational-level barriers as the largest category of barriers to enacting leadership and suggested that removing these barriers will enable NP's leadership potential (Elliott, 2017; Higgins et al., 2014). Furthermore, lack of a shared vision between NPs and the managerial level was a potential barrier, too. It is likely that NPs' expertise will be more effective in organisations with a clear communication about their roles and responsibilities (Brooten, Youngblut, Deosires, Singhala, \& GuidoSanz, 2012). In accordance with the participants, more support and effort from management, other healthcare professionals and other NPs could facilitate the reallocation of tasks (Carnwell \& Daly, 2003; Zwijnenberg \& Bours, 2012).

Some of the participants had difficulty to position themselves without having colleagues to support them, in line with findings by Cronenwett (2012) and Brooten et al. (2012). Besides, Nursing Advisory Councils within the hospital did not seem eligible for representation of NPs hospital-wide, according to some participants. Furthermore, participants indicated that a general job description could do away with any ambiguity about the NP function. Leadership ability of NPs is dependent on having a national job description in which the leadership component is specified. Development of a standard with the involvement of all clinicians will enhance role clarity and reduce resistance of the multidisciplinary team (Higgins et al., 2014). All participants had experienced that others were confused about the NP profession in view of the name of the function and the overlap in scope of practice with the physician assistant. Consistency and understandability are necessary for developing the full potential of NPs (Bryant-Lukosius, Dicenso, Browne, \& Pinelli, 2004; Hamric et al., 2014).

\section{2 | Study limitations}

Some limitations of the study need to be addressed. First, NPs are a young professional group with a great deal of working areas. This makes it difficult to generalise this sample to all NPs in the country. However, the completion of the sample of fifteen NPs with three NPs that did not meet the exact inclusion criteria with regard to work experience demonstrated that the results found might be representative for a larger group of NP professionals. Moreover, the aim of the study was to explore the experiences of a sample of NPs. Second, several participants saw similarities between their current role as NP and former function as specialised nurse, although they do feel more accountable and responsible as a NP. Perhaps we should have focused on the participants' feelings or personal effectiveness rather than the role description, since both NPs and registered specialised nurses in the Netherlands are trained to seamlessly integrate the competencies of all seven CanMEDS roles (Lambregts \& Grotendorst, 2012; Ter Maten-Speksnijder, Grypdonck, Pool, Meurs, \& van Staa, 2015). Third, the purposive sampling method used in this study could have led to selection bias as participants were selectively approached by the educational coordinators. Furthermore, all participants had knowledge of and interest in the topic and this may indicate they were more actively involved in the positioning of NPs than others. Nevertheless, judgements and inclusion criteria were based on clear criteria. Last, the findings from this study are limited to the perspectives of the NPs themselves. Inclusion of physicians and management could have provided different views on the leadership execution.

\section{6 | CONCLUSION}

This study on the perception of one's ability to enact leadership shows that an adequate use of leadership is crucial for role development and positioning of NPs. Although differences in tasks between NPs and specialised nurses appeared to be clear, NPs mainly enact leadership on clinical level. It is a major challenge for individual NPs, healthcare organisations and educational institutions to create a full and unambiguous scope of expertise and practice. This development may enable NPs to clearly show the added value of this profession in the healthcare system.

\section{RELEVANCE TO CLINICAL PRACTICE}

A profitable use of NPs' leadership competencies could lead to further role development and a better positioning of NPs. Leadership in nursing is of great importance since it is directly linked to quality of care, positive patient outcomes, cost-effectiveness and productivity in healthcare settings (Australian College of Nursing, 2015; Wong, Cummings, \& Ducharme, 2013). Universities could focus on increasing NP's perceived self-efficacy to be prepared for the challenging role. For NPs themselves, it is important to be involved in daily work interventions on different organisational levels, like more involvement in policy-related decisions or research activities (Heinen, van Oostveen, Peters, Vermeulen, \& Huis, 2019). A primary focus on medical practice will not improve further positioning of the profession (Hamric et al., 2014). Moreover, physicians' recognitions about the NP profession are of great importance and their demands should be in line with the NP's qualifications. Besides, more support and effort from management are needed for further 
development and positioning of NPs (Elliott, 2017; Higgins et al., 2014). For example, being encouraged to conduct research or being involved in policy-related activities will help NPs to adequately establish their position. Managers need to consider the importance of an established and common vision with all staff members. Nurse associations can play a more active role in the clarification of NP's scope of practice. Establishing NPs as an independent professional group and clearly defined work profiles will contribute to further positioning of the NP's profession. Further research on the perceptions of all disciplines may help in achieving this.

\section{ACKNOWLEDGEMENTS}

We would like to express our gratitude to the interviewees, who were all willing to share their experiences with us.

\section{CONFLICT OF INTEREST}

The authors declare no conflict of interest.

\section{ORCID}

Julia van Kraaij iD https://orcid.org/0000-0001-5907-1960

Catharina van Oostveen (iD https://orcid.

org/0000-0002-3483-2206

\section{REFERENCES}

Antrobus, S., \& Kitson, A. (1999). Nursing leadership: Influencing and shaping health policy and nursing practice. Journal of Advanced Nursing, 29(3), 746-753. https://doi.org/10.1046/j.1365-2648.1999. 00945.x

Australian College of Nursing (2015). Nurse Leadership. A White Paper by ACN. Retrieved from https://www.acn.edu.au/wp-content/uploa ds/2017/10/acn_nurse_leadership_white_paper_reprint_2017_web.pdf

Begley, C., Murphy, C., Higgins, A., Elliott, N., Lalor, J., Sheerin, F., ... MacNeela, P. (2010). Evaluation of Clinical Nurse and Midwife Specialist and Advanced Nurse and Midwife Practitioner Roles in Ireland (SCAPE). Final Report. National Council for the Professional Development of Nursing and Midwifery in Ireland, Dublin.

Brooten, D., Youngblut, J. M., Deosires, W., Singhala, K., \& Guido-Sanz, F. (2012). Global considerations in measuring effectiveness of advanced practice nurses. International Journal of Nursing Studies, 49, 906-912. https://doi.org/10.1016/j.ijnurstu.2011.10.022

Bryant-Lukosius, D., Dicenso, A., Browne, G., \& Pinelli, J. (2004). Advanced practice nursing roles: Development, implementation and evaluation. Journal of Advanced Nursing, 48(5), 519-529. https://doi. org/10.1111/j.1365-2648.2004.03234.x

Carnwell, R., \& Daly, W. M. (2003). Advanced nursing practitioners in primary care settings: An exploration of the developing roles. Journal of Clinical Nursing, 12, 630-642. https://doi. org/10.1046/j.1365-2702.2003.00787.x

Carryer, J., Gardner, G., Dunn, S., \& Gardner, A. (2007). The core role of the nurse practitioner: Practice, professionalism and clinical leadership. Journal of Clinical Nursing, 16, 1818-1825. https://doi. org/10.1111/j.1365-2702.2007.01823.x

Cronenwett, L. R. (2012). Molding the future of advanced practice nursing. Nursing Outlook, 60, 241-249. https://doi.org/10.1016/j.outlo ok.2012.06.010

Delamaire, M., \& Lafortune, G. (2010). Nurses in Advanced Roles: A Description and Evaluation of Experiences in 12 Developed Countries, OECD Health Working Papers, 54, OECD Publishing, http:// dx.doi.org/10.1787/5kmbrcfms5g7-en
Denker, A., Sherman, R. O., Hutton-Woodland, M., Brunell, M. L., \& Medina, P. (2015). Florida nurse leader survey findings. Key leadership competencies, barriers to leadership, and succession planning needs. The Journal of Nursing Administration, 45(7/8), 404-410. https://doi.org/10.1097/NNA.0000000000000222

Dicenso, A., \& Bryant-Lukosius, D. (2010). Clinical Nurse Specialists and Nurse Practitioners in Canada. A decision support synthesis. Retrieved from https://www.cfhi-fcass.ca/sf-docs/default-source/commission ed-research-reports/Dicenso_EN_Final.pdf?sfvrsn=0

Elliott, N. (2017). Building leadership capacity in advanced nurse practitioners - the role of organisational management. Journal of Nursing Management, 25, 77-81. https://doi.org/10.1111/jonm.12444

Elliott, N., Begley, C., Sheaf, G., \& Higgins, A. (2016). Barriers and enablers to advanced practitioners' ability to enact their leadership role: A scoping review. International Journal of Nursing Studies, 60, 24-45. https://doi.org/10.1016/j.ijnurstu.2016.03.001

Elliott, N., Higgins, A., Begley, C., Lalor, J., Sheerin, F., Coyne, I., \& Murphy, K. (2013). The identification of clinical and professional leadership activities of advanced practitioners: Findings from the Specialist Clinical and Advanced Practitioner Evaluation study in Ireland. Journal of Advanced Nursing, 69(5), 1037-1050. https://doi. org/10.1111/j.1365-2648.2012.06090.x

Epstein, R. M., \& Hundert, E. M. (2002). Defining and Assessing Professional Competence. JAMA, 287(2), 226-235. https://doi.org/ 10.1001/jama.287.2.226

Fealy, G. M., Casey, M., O'Leary, D. F., McNamara, M. S., O'Brien, D., O'Connor, L., ... Stokes, D. (2018). Developing and sustaining specialist and advanced practice roles in nursing and midwifery: A discourse on enablers and barriers. Journal of Clinical Nursing, 27, 3797-3809. https://doi.org/10.1111/jocn.14550

Gardner, A., \& Gardner, G. (2005). A trial of nurse practitioner scope of practice. Journal of Advanced Nursing, 49(2), 135-145. https://doi. org/10.1111/j.1365-2648.2004.03273.x

Hamric, A. B., Hanson, C. M., Tracy, M. F., \& O'Grady, E. T. (2014). Advanced practice nursing, an integrative approach (5th Edition ed.). Philadelphia, USA: Elsevier Saunders.

Heinen, M., van Oostveen, C., Peters, J., Vermeulen, H., \& Huis, A. (2019). An integrative review of leadership competencies and attributes in advanced nursing practice. Journal of Advanced Nursing, 75, 23782392. https://doi.org/10.1111/jan.14092

Herzog, H. (2005). On home turf: Interview location and its social meaning. Qualitative Sociology, 28(1), 25-47. https://doi.org/10.1007/ s11133-005-2629-8

Higgins, A., Begley, C., Lalor, J., Coyne, I., Murphy, K., \& Elliott, N. (2014). Factors influencing advanced practitioners' ability to enact leadership: A case study within Irish healthcare. Journal of Nursing Management, 22, 894-905. https://doi.org/10.1111/jonm.12057

Johnson, J. M. (2011). In-Depth Interviewing. In J. R. Gubrium, \& J. A. Holstein (Eds.), Handbook of interview research (pp. 103-119). London, UK: SAGE Publications Ltd.

Lamb, A., Martin-Misener, R., Bryant-Lukosius, D., \& Latimer, M. (2018). Describing the leadership capabilities of advanced practice nurses using a qualitative descriptive study. Nursing Open, 5, 400-413. https ://doi.org/10.1002/nop2.150

Lambregts, J., \& Grotendorst, A. (2012). Leren van de toekomst. Verpleegkundigen en verzorgenden 2020 Deel 1. [Future learning. Nurses 2020 part 1]. Houten, the Netherlands: Bohn Stafleu van Loghum.

LeMahieu, P. G., Nordstrum, L. E., \& Gale, D. (2017). Positive deviance: Learning from positive anomalies. Quality Assurance in Education, 25(1), 109-124.

Mantzoukas, S., \& Watkinson, S. (2006). Review of advanced nursing practice: The international literature and developing generic features. Journal of Clinical Nursing, 16, 28-37. https://doi. org/10.1111/j.1365-2702.2006.01669.x 
Milne, J., \& Oberle, K. (2005). Enhancing rigor in qualitative description: A case study. Journal of Wound, Ostomy, and Continence Nursing, 32(6), 413-420.

Neergaard, M. A., Olesen, F., Andersen, R. S., \& Sondergaard, J. (2009). Qualitative description - the poor cousin of health research? BMC Medical Research Methodology, 9(52), https://doi. org/10.1186/1471-2288-9-52

Palinkas, L. A., Horwitz, S. M., Green, C. A., Wisdom, J. P., Duan, N., \& Hoagwood, K. (2015). Purposeful sampling for qualitative data collection and analysis in mixed method implementation research. Administration and Policy in Mental Health, 42(5), 533-544. https://doi.org/10.1007/s10488-013-0528-y

Patrick, A., Laschinger, H. K. S., Wong, C., \& Finegan, J. (2011). Developing and testing a new measure of staff nurse clinical leadership: The clinical leadership survey. Journal of Nursing Management, 19, 449-460. https://doi.org/10.1111/j.1365-2834.2011.01238.x

Petersen, P. A., Keller, T., Way, S. M., \& Borges, W. J. (2015). Autonomy and empowerment in advanced practice registered nurses: Lessons from New Mexico. Journal of American Association of Nurse Practitioners, 27, 363-370. https://doi.org/10.1002/2327-6924.12202

Price, P. C., Jhangiani, R. S., \& Chiang, I. A. (2015). Research methods in psychology ( $2^{\text {nd }}$ Canadian Edition). Retrieved from https://opent extbc.ca/researchmethods/

Scott, E. S., \& Miles, J. (2013). Advancing Leadership Capacity in Nursing. Nursing Administration Quarterly, 37(1), 77-82. https://doi. org/10.1097/NAQ.0b013e3182751998

Schober, M. (2016). Introduction to advanced nursing practice. An international focus. New York, USA: Springer Publishing.

Skår, R. (2008). The meaning of autonomy in nursing practice. Journal of Clinical Nursing, 19, 2226-2234. https://doi. org/10.1111/j.1365-2702.2009.02804.x

Streubert, H. J., \& Carpenter, D. R. (2001). Qualitative research in nursing. Advancing the humanistic imperative (5th ed.). Philadelphia, USA: Lippincott Williams \& Wilkins.

Ter Maten-Speksnijder, A., Grypdonck, M., Pool, A., Meurs, P., \& van Staa, A. (2015). Learning to attain an advanced level of professional responsibility. Nurse Education Today, 35, 954-959. https://doi. org/10.1016/j.nedt.2015.03.005

Tong, A., Sainsbury, P., \& Craig, J. (2007). Consolidated criteria for reporting qualitative research (COREQ): A 32-item checklist for interviews and focus groups. International Journal for Quality in Health Care, 19(6), 349-357. https://doi.org/10.1093/intqhc/mzm042
Van Oostveen, C. J., Goedhart, N. S., Francke, A. L., \& Vermeulen, H. (2017). Combining clinical practice and academic work in nursing: A qualitative study about perceived importance, facilitators and barriers regarding clinical academic careers for nurses in university hospitals. Journal of Clinical Nursing, 26, 4973-4984. https://doi. org/10.1111/jocn.13996

Vulto, M., \& Vianen, G. (2009). Toekomstige behoefte verpleegkundig specialisten bij somatische aandoeningen. Een zoektocht in onontgonnen gebied. [The future demand for nurse specialists with expertise in somatic disorders]. Retrieved from http://www.marijvulto.nl/wp-conte nt/uploads/bw-VBOC-09.pdf

V\&VN (2018). The Nurse Practitioner in the Netherlands. Retrieved from https://vsregister.venvn.nl/Registratie/Buitenslands-gediplomee rden

Weiland, S. (2015). Understanding nurse practitioner autonomy. Journal of the American Association of Nurse Practitioners, 27, 95-104. https:// doi.org/10.1002/2327-6924.12120

Wong, C. A., Cummings, G. G., \& Ducharme, L. (2013). The relationship between nursing leadership and patient outcomes: A systematic review update. Journal of Nursing Management, 21, 709-724. https:// doi.org/10.1111/jonm.12116

Zwijnenberg, N. C., \& Bours, G. J. J. W. (2012). Nurse practitioners and physician assistants in Dutch hospitals: Their role, extent of substitution and facilitators and barriers experienced in the reallocation of tasks. Journal of Advanced Nursing, 68(6), 1235-1246. https://doi. org/10.1111/j.1365-2648.2011.05823.x

\section{SUPPORTING INFORMATION}

Additional supporting information may be found online in the Supporting Information section.

How to cite this article: van Kraaij J, van Oostveen C, Vermeulen $\mathrm{H}$, et al. Nurse practitioners' perceptions of their ability to enact leadership in hospital care. J Clin Nurs. 2020;29:447-458. https://doi.org/10.1111/jocn.15105 